\title{
INNOVATIVE RESEARCH ABOUT SCHOOL TEACHERS STRESS AND SUSTAINABLE STRATEGIES TO ELIMINATE SCHOOL TEACHERS STRESS
}

\author{
${ }^{1}$ Dr.V.SUMATHY
}

\begin{abstract}
The worker's response to work stress can be either psychological, physical or both and is usually categorized as being acute, post traumatic, or chronic. National surveys in the United Kingdom, Australia and India have reported a serious and growing problem of academic work stress with several deleterious consequences including decreased job satisfaction, reduced morale and ill health for academic staff. The outcome of stress may be of: emotional manifestations, dissatisfaction, depression, feelings of undefined anxiety, fear and low self-esteem with a possible extreme result being burnout; behavioral manifestations behavioral issues such as hungry disorders, excessive smoking and alcohol or drug abuse, violence, sleep disorders, possible displays of withdrawal symptoms that is absence and resignations from the profession.
\end{abstract}

Key words-- Work stress, Labour welfare, stress management, Teacher stress, and Coping Stress.

\section{INTRODUCTION}

Stress may be a non-specific demand on the individual's body or mind to adapt a modification physically or psychologically. The term stress is used to describe the feeling of a person who is required to deviate from normal to self desired functioning in the work place as the result of opportunities, constraints or demands relating to potentially important work related outcomes KalikaYadav(2012). The impact of stress in the workplace on the employee's physical health, mental well-being and effectiveness in the workplace has been increasingly recognized in recent years.

\section{Impact of Teachers Stress In The Present Situation In India}

The economic process and privatization of the education system in numerous countries and in india forced the upper education to be additional competent thus on manufacture the stakeholders with higher knowledge, accommodativeness, skills and competencies which are essential for survival in the world market. In tune with this, the Indian education system had undergone rapid changes in terms of expansion, privatization, marketization, curricular reforms and pedagogical innovations. These changes have challenged the universities in terms of quality education, shortage of faculty of high caliber, ineffective teaching methods, outmoded curriculum and evaluation system, lack of appropriate reading materials, poor infrastructure facilities, faulty administration, faculty admission criteria, inability to attract and retain talented minds and absence of

\footnotetext{
${ }^{1}$ M.B.A, M.Phil.,Ph.D, Assistant Professor, Department of Business Administration, Thiru Kolanjiyappar Government Arts College, Vrithachalam, TamilnaduIndia, vsumathysenthil@yahoo.co.in
} 
academically conducive atmosphere. Further, the increasing role compete by latest information, skills, innovation and research in economic growth and development, the emergence of the information society and the need for quality education results in hyperbolic pressure on the upper education system and lecturers specifically. These factors in-turn adversely affects the standard of our education system and creates varied stressors and strain in lecturers that any deteriorates their performance

\section{Causes of Non-Organisational Stress}

Certain factors outside the scope of an organisation also cause stress. These stressors not based on the result of organisational factors. These main sources or causes of non-organisational stress are:-

- Civic Amenities: Poor civic amenities in the area in which one lives can be a cause of stress. Inadequate or lack of civic facilities like improper water supply, excessive noise or air pollution, lack of proper transport facility can be quite stressful.

- Life Changes: Life changes can bring stress to a person. Life changes can be slow or sudden. Slow life changes include getting older and sudden life changes include death or accident of a loved one. Sudden life changes are highly stressful and very difficult to cope.

- Frustration: Frustration is another cause of stress. Frustration arises when goal directed behaviour is blocked. Management should attempt to remove barriers and help the employees to reach their goals.

- Caste and Religion Conflicts: Employees living in areas which are subject to caste and religious conflicts do suffer from stress. In case of religion, the minorities and lower-caste people (seen especially in India) are subject to more stress.

- Personality: People are broadly classified as 'Type A' and 'Type B'.

- Feels guilty while relaxing.

- Gets irritated by minor mistakes of self and others.

- Feels impatient and dislikes waiting.

- Does several things at one time.

- While the 'Type B' people are exactly opposite and hence are less affected by stress due to above mentioned factors.

- Technological Changes: When there are any changes in technological field, employees are under the constant stress of fear of losing jobs, or need to adjust to new technologies. This can be a source of stress.

- Career Changes: When a person suddenly switches over a new job, he is under stress to shoulder new responsibilities properly. Under promotion, over promotion, demotion and transfers can also cause stress.

\section{COPING STRATEGIES}

Dealing with problems or difficulties in a calm and appropriate manner is commonly referred to as coping. How a teacher copes with stress in the school environment affects the impact of stress on their psychological well-being and on physiological response (Griffith, Steptoe, \&Cropley, 1999). Coping behaviors or resources come in the form of physical, psychological, social, or material factors and help teachers overcome job-related stressors and achieve their valued outcomes with students (Blasé, 1982). Common positive strategies teachers use to alleviate stress include exercise, social resources, avoidance, reading, hobbies, movement, and meditation 
(Gulwadi, 2006). and meditation (Gulwadi, 2006). These coping ways utilized by academics have an effect on their outlook on matters, thereby fixing the perception of stress (Griffith, Steptoe, \&Cropley, 1999). To alter the perception of stress, academics might invoke inward or outward coping ways. Inward ways, like concentrating on one thing narrow within the field of stimuli around oneself, embrace seeking stillness and focus. Outward ways, like exercise, involve seeking connections, distractions, and movement (Gulwadi, 2006). Although there are several common coping ways obtainable, most academics think about social support, active designing, restorative experiences, and suppression of competing behaviors.

\section{Active Coping}

In general, active coping refers to the utilization of those psychological or behavioral coping efforts that are characterized by an attempt to use one's own resources to deal with a problem situation. Some of active coping strategies are as follows:

\section{Planning}

In organizations, designing could be a management method, involved with process goals for company's future direction and decisive on the missions and resources to attain that concentrate on. To meet the goals, heads of the organisation may develop plans Planning always has a purpose. The purpose is also action of bound goals or targets. Planning increases the efficiency of an organization. It reduces the risks concerned in trendy business activities. It facilitates proper coordination within an organization. It aids in organizing all available resources. It gives right direction to the organization.

\section{Emotional Support}

Emotional support is viewed by each theorists and laypeople as a basic provision of shut personal relationships (Cunningham \& Barbee, 2000) and area unit a very important determinant of satisfaction inside these relationships. People value the emotional support skills of their relationship partners, and perceptions of emotional supportiveness have been found to play a critical role in the development and maintenance of friendships, romances, families, and work relationships When emotional support is provided skillfully (i.e., addresses a distressed other's feelings in a sensitive and effective way), it can yield numerous benefits for the recipient, including improvements in emotional states coping and even health (Burleson, 2003)

\section{Instrumental Support}

Tangible support is that the provision of economic help, material goods, or services. Also known as instrumental support, this form of social support encompasses the concrete, direct ways people assist others. Providing instrumental support to friends, relatives, and neighbors, or emotional support to spouses has been linked to a significant decrease in the risk for mortality.

\section{Palliative Coping}

Palliative strategies do not deal with the source of stress, but are aimed at lessening the negative feelings associated with stress (Kyriacou, 2000). Palliative strategies can be physical or mental. Mental techniques are 
any strategy that allows a teacher to alter his/her appraisal of a situation. If a teacher can view a situation as less threatening then that will help to alleviate the experience of stress. The four main mental strategies are putting things into perspective, seeing the humor in situations, thinking positively, and maintaining emotional control. Physical palliative techniques are also strategies that a teacher can use to reduce the negative feelings generated by stress.

\section{Positive Reinforcing}

In behaviorism, positive reinforcement occurs when a reward, sometimes called reinforce, is given for a specific desired behavior. Other behaviors, even those who are negative, area unit merely neglected. Over time, this may cause a rise within the desired behavior. Positive reinforcement should be personalized to the precise person receiving it. What reinforces one person's behavior might not have a similar impact on somebody else.

\section{Acceptance}

Acceptance - "An categorical act or implication by conduct that manifests assent to the terms of provide|asuggestion|a proposal $\}$ in a very manner invited or needed by the offer so a binding contract is formed. The exercise of power conferred by a proposal by performance of some act.The act of someone to whom one thing is obtainable of tendered by another, whereby the offered demonstrates through an act invited by the offer an intention of retaining the subject of the offer."

\section{Humour}

Humour is that the tendency of explicit psychological feature experiences to impress laughter and supply amusement. The term derives from the humoural drugs of the traditional Greeks, which taught that the balance of fluids in the human body, known as humours (Latin: humor, "body fluid"), control human health and emotion

\section{Religion}

"A faith could be a unified system of beliefs and practices relative to sacred things, that is to say, things set apart and forbidden — beliefs and practices which unite into one single moral community known as a Church, all those who adhere to them."

\section{Self-Distraction}

Self-destruction is usually defined as "The voluntary destruction of something by itself." In human personality terms, we are really talking about self-destructive behaviour patterns which can cause oneself irreparable harm or damage, either deliberately or inadvertently.

\section{Denial}

Denial could be a defense reaction during which someone unconsciously rejects thoughts, feelings, needs, wishes, or external realities that they would not be able to deal with if they got into the conscious mind. For example, when people are told that they have a terminal illness and are going to die in a short period of time, the 
news can be so overwhelming that they enter into a state of denial--they refuse to accept that they are going to die soon because it is much too pain full to handle.

\section{Substance Abuse}

Substance abuse, also known as drug abuse, is a patterned use of a substance (drug) in which the user consumes the substance in amounts or with methods neither approved nor supervised by medical professionals. Substance abuse/drug abuse isn't restricted to mood-altering or psycho-active medicine. If associate degree activity is performed mistreatment the objects against the principles and policies of the matter (as in steroids for performance improvement in sports), it is also called substance abuse. Therefore, mood-altering and mindaltering substances don't seem to be the sole kinds of medicine abused. Using illicit medicine - narcotics, stimulants, depressants (sedatives), hallucinogens, cannabis, even glues and paints, also are thought-about to be classified as drug/substance abuse. Substance abuse often includes problems with impulseRelationship between Teachers Stress anddimensions of Organisational Climate.

Table 1: Relationship between Teachers Stress and dimensions of Organisational Climate

\begin{tabular}{|c|c|c|c|c|c|}
\hline $\begin{array}{c}\text { Organisational } \\
\text { Climate }\end{array}$ & $\begin{array}{c}\text { Supportive } \\
\text { Behaviour }\end{array}$ & $\begin{array}{l}\text { Directive } \\
\text { Behaviour }\end{array}$ & $\begin{array}{c}\text { Engaged } \\
\text { Behaviour }\end{array}$ & $\begin{array}{l}\text { Frustrated } \\
\text { Behaviour }\end{array}$ & $\begin{array}{r}\text { Intimate } \\
\text { Behaviour }\end{array}$ \\
\hline $\begin{array}{l}\text { Directive } \\
\text { Behaviour }\end{array}$ & $.701^{*}$ & & & & \\
\hline $\begin{array}{c}\text { Engaged } \\
\text { Behaviour }\end{array}$ & $.744^{*}$ & $.961^{*}$ & & & \\
\hline $\begin{array}{l}\text { Frustrated } \\
\text { Behaviour }\end{array}$ & $.728^{*}$ & $.469^{*}$ & $.476^{*}$ & & \\
\hline $\begin{array}{c}\text { Intimate } \\
\text { Behaviour }\end{array}$ & $.491^{*}$ & $.689^{*}$ & $.673^{*}$ & $.512^{*}$ & \\
\hline Teachers Stress & $.509^{*}$ & $.283^{*}$ & $.311^{*}$ & $.807^{*}$ & $.487^{*}$ \\
\hline
\end{tabular}

While testing about the correlations between teacher stress and organisational climate dimension teachers frustrated behaviour has the highest percentage of influence i.e. 80.7 percent over the teachers stress. And the Frustrated Behaviour has the positive and significance relationship with teacher stress. The incidence of stress and burnout area unit sometimes high for human service professionals, including teachers. Stress describes negative feelings ensuing from work that will embody anger, frustration, tension and/or depression that threaten a professional's sense of well-being (Howard et al 2004). There are variations in the results; the lowest relationship with teacher stress is 0.283 Directive behaviour of principal behaviour. The next highest influence over the teacher stress to directive behaviour is engaged behaviour of teachers in the school. There are some similarities between the influence of supportive behaviour of principle and intimate behaviour of teachers in effect to teachers stress. 
Table 2: Relationship between Teachers Stress and dimensions of Work Family Variable

\begin{tabular}{|l|c|c|}
\hline \multicolumn{1}{|c|}{ Work Family Variable } & Work Family Conflict & Family Work conflict \\
\hline Family Work conflict & $.501^{*}$ & $\mathbf{. 8 9 1}^{*}$ \\
\hline Teachers Stress & $.335^{*}$ & \\
\hline
\end{tabular}

The above table inferred that the comparison between the influences of teacher stress with the dimensions Work Family Conflict and Family Work conflict. It is clearly depicts that the dimension family work conflict has the highest percentage of influence on teachers stress i.e 89.1 percent. The work family conflict has the contrast over family work conflict; the relationship between work family conflicts has the positive and significant relationship over teacher stress. It shows that the demands of family or spouse/partner of the respondents interfere with work-related duties. In order to get a better grasp of how these two facets work together resulting in the overall work-family conflict construct, several researchers have examined and compared the antecedents and consequences of each work-family conflict and family-work conflict. Frone (1992) examined the antecedents and outcomes of both types of conflict, also he hypothesized that job stressors and job involvement would predict work-family conflict which would in turn predict family distress and depression, while family involvement and family stressors would predict family-work conflict which would in turn predict job distress and depression.

Table 3: Relationship between Teachers Stress and dimensions of Coping Strategies

\begin{tabular}{|l|c|c|}
\hline \multicolumn{1}{|c|}{ Coping Strategies } & Direct Active Coping & Palliative Coping \\
\hline Palliative Coping & $.812^{*}$ & \\
\hline Teachers Stress & $.468^{*}$ & $.678^{*}$ \\
\hline
\end{tabular}

The above table explains that the palliative coping strategies has the highest influence over teachers stress and the percentage for that relationship is 67.8 percentage, the strategies that are considered under palliative coping are Positive Reinforcing, Acceptance, Humour, Religion, Self Distraction, Denial and Substance Abuse. So, much of the respondents has the awareness about stress coping strategies after having experience with job stress. And the results show that the prevention about teacher stress is only practiced by 46.8 percent of the respondents. Kyriacou (2001) dichotomizes coping ways into direct action and palliative techniques. Palliative techniques don't alter the supply of stress itself, but focus on reducing the feelings of stress from those sources. Some ways could also be physical in nature, such as relaxation training aimed at reducing feelings of tension and anxiety. Others could also be mental and involve the teacher modifying however they appraise trying things 
Table 4: Multiple Regression Analysis

\begin{tabular}{|c|c|c|c|c|c|}
\hline Model & Sum of Squares & Df & Mean Square & F & Sig. Value \\
\hline Regression & 174507.09 & 6 & 34901.41 & \multirow{2}{*}{$\mathbf{7 1 8 . 7 4}$} & $\mathbf{0 . 0 0}^{\mathbf{a}}$ \\
\hline Residual & 18646.66 & 384 & 48.55 & & \\
\hline Total & 193153.76 & 390 & & \\
\hline
\end{tabular}

Predictors: (Constant), Family Work Conflict, Emotional Demands, Teachers Behaviour, Work Family Conflict, Turnover Intension

Table 5 : Multiple Regression Analysis

\begin{tabular}{|c|c|c|c|c|c||}
\hline \multirow{2}{*}{ Model } & \multicolumn{2}{|c|}{ Un-standardized Coefficients } & Standardized Coefficients & \multirow{2}{*}{$\begin{array}{c}\text { Sig. } \\
\text { Value }\end{array}$} \\
\cline { 2 - 6 } & B & Std. Error & Beta & -5.66 & 0.00 \\
\hline (Constant) & -17.04 & 3.00 & -0.01 & -0.75 & 0.45 \\
\hline Emotional Demands & -0.02 & 0.03 & 0.58 & 18.77 & 0.00 \\
\hline Turnover Intension & 2.53 & 0.13 & 0.34 & 14.02 & 0.00 \\
\hline Teachers Behaviour & 0.46 & 0.03 & 0.14 & 5.06 & 0.00 \\
\hline Work Family Conflict & 0.47 & 0.09 & 0.33 & 8.83 & 0.00 \\
\hline Family Work Conflict & 1.64 & \multicolumn{2}{|c|}{0.18} & & \\
\hline \multicolumn{7}{|c|}{ Dependent Variable: Teachers Stress } \\
\hline
\end{tabular}

Dependent Variable: Teachers Stress

From the R-square value it is observed that the selected independent variables have $90.2 \%$ influence on the dependent variable i.e. teacher stress. The observed F-value 718.74 and its corresponding p-value 0.00 also confirm this. From the 't' value it is observed that turnover intension, teachers behaviour, work family conflict and family work conflict are the dependent variable which significantly influence teachers stress. Whereas the dimension emotional demands do not have significant influence on teacher stress.

\section{Reliability test for Data Collection Instrument}

Reliability means the ability of a measuring instrument to give accurate and consistent results. The question of reliability arises only for the questions used to measure attitude which cannot be accurately measured. In this research, statements are used to measure Individual Demands at Work and Teachers Job Stress Level. For all the statements five points Likert scale is used. Initially, alpha value was considered for the data collected over pilot study. This survey has been conducted not only for testing reliability of instruments but also for making required 
Changes in the questionnaire in order to elicit necessary information from respondents. The questionnaire has been altered according to the feedback given by the respondents during the initial pilot study. The altered questionnaire is again put under reliability test with another thirty respondents. The Cronbach alpha value has been calculated again for the final set of respondents. The measured reliability values are presented in the following table

Table 6: Cronbach Alpha Tests for Reliability

\begin{tabular}{|c|c|c|c|}
\hline Sl.No & Variable & $\begin{array}{c}\text { Cronbach's Alpha if Item } \\
\text { Deleted }\end{array}$ & $\begin{array}{c}\text { Cronbach's } \\
\text { Alpha }\end{array}$ \\
\hline \multicolumn{4}{|c|}{ Individual Demands At Work } \\
\hline 1 & Quantitative demands & 0.72 & \multirow{5}{*}{0.73} \\
\hline 2 & Cognitive demands & 0.71 & \\
\hline 3 & Work pace & 0.68 & \\
\hline 4 & Emotional demands & 0.66 & \\
\hline 5 & Demands for hiding emotions & 0.64 & \\
\hline \multicolumn{4}{|c|}{ Teachers Job Stress } \\
\hline 1 & Supervisory Support & 0.92 & \multirow{7}{*}{0.93} \\
\hline 2 & Role ambiguity & 0.93 & \\
\hline 3 & Role Stress & 0.91 & \\
\hline 4 & Organizational management & 0.92 & \\
\hline 5 & Jobs Satisfaction & 0.92 & \\
\hline 6 & Life Satisfaction & 0.91 & \\
\hline 7 & Task Stress & 0.92 & \\
\hline
\end{tabular}

From the above table it is clear that the alpha values are more than 0.6 which means the statements used to measure the variables are reliable. The SPSS software was used to calculate the Cronbach $\alpha$ coefficients. The Cronbach $\alpha$ coefficients for all of the theoretical constructs exceeded the recommended reliability threshold. Furthermore, the overall Cronbach $\alpha$ coefficient for this construct was 0.73 and 0.93 , well above the critical value.

\section{SUGGESTIONS}

- It is suggested that effective measures has to be taken by schools management especially private Schools for creating a conductive environment in the schools so, that teachers do not have high level of Job Stress in order to promote effective teaching among to the students.

- It is also, suggested that private school should provide parity to teachers in the regard to pay scale and other facilities being offered to government teachers.

- It is also suggested that social security in terms of job be provided to teacher working in private schools as provide to government teachers. 
- It is also suggested that some recreational programmes be organized for stressing out the stress of teachers working schools in regular basis in order to promote positive mental health among teachers.

- It is also suggested that there should not be too much of extra teaching load on private school teachers and there should be sufficient number of teachers working in private schools with proper teacher's pupil ratio to avoid Job Stress.

- Teachers' working conditions should be improved by providing some social facilities such as smart classes, computers with Internet connections, so that they can use them as coping strategies for stress

- Teachers should also create time for themselves to relax in some designated recreation centers.

- Teachers should cultivate the habit of playing sports as a means to cope with stress.

- The school curriculum should be restructured to include both teachers-centered and students-centered co-curricular activities as regards to inter-house sporting activities in the schools

- All teachers in the schools should have general knowledge of health education to be able to cater for their well-being at work and beyond.

- The school management should provide a health risk appraisals which helps in testing their teachers stress levels. Trying to openly resolve conflicts at work and even seeking outside support from counselors, support groups or co-workers can bring a sea change in a person's attitude to handle stress.

\section{REFERENCES}

1. KalikaYadav and AlpanaVerma (2012), Occupational Stress among Higher Secondary School Teachers: a field Study, Samwaad:e-journal,Vol.1 no.1,ISSN:2277-7490.

2. Griffith, J., Steptoe, A., and Cropley, M. (1999), An Investigation of Coping Strategies Associated with Job Stress in Teachers. British Journal of Educational Psychology, 69 (4), pp 517-531.

3. GowriBetrabetGulwadi(2006), Seeking Restorative Experiences Elementary School Teachers' Choices for Places That Enable Coping With Stress, Environment And Behavior, Vol. 38 No. 4, July 2006503 520, DOI: 10.1177/0013916505283420.

4. Cunningham, M. R., \& Barbee, A. P. (2000), Social support. In C. Hendrick\& S. S. Hendrick (Eds.),Close relationships: A sourcebook (pp. 272-285). Thousand Oaks, CA: Sage.

5. Burleson, B. R. (2003), The experience and effects of emotional support: What the study of cultural and gender differences can tell us about close relationships, emotion, and interpersonal communication. Personal Relationships, 10, 1-23.

6. Kyriacou, C (2001), Teacher stress: Directions for future research. Education Review, 53, $27-53$.

7. Howard, S. \& Johnson, B. (2004), Resilient teachers: Resisting stress and burnout. Social Psychology of Education, 7, 399-420.

8. Frone, M. R., Russell, M., \& Cooper, M.L. (1992), Antecedents and outcomes of work-family conflict: Testing a model of the work-family interface. Journal of Applied Psychology, 77, 65-78. 